\section{ANALYSIS OF DELAMINATION IN DRILLING OF COMPOSITE MATERIALS}

\author{
Brno UT, Faculty of Mechanical Engineering Brno, Czech Republic \\ e-mail: ysedla10@fme.vutbr.cz
}

The aim of this work is to clarify the interaction mechanisms between the drilling tool and material. Among the defects caused by drilling, delamination appears as to be of the most critical and may occurs at both the entrance and exit plane. This paper presents

a prediction Hocheng-Dharan model of thrust force for drilling without delamination. HSS twist drills with different geometry were used for drilling of carbon/epoxy composites. Experiments were performed to validate physical model of delamination and investigate the effect of tool geometry and drilling paramenters on delamination. The results showed that proposed delamination model is adequate and that damage around drilling hole can be reduced significantly by proper selection of drilling conditions.

Keywords composite materials, delamination, drilling, tool wear

\section{Introduction}

Machining composite materials is a rather complex task owing to its heterogeneity, heat sensitivity, and to the fact that reinforcements are extremely abrasive. Drilling is a frequently practiced machining process in industry owing to the need for component assembly in mechanical pieces and structures. On the other hand, drilling laminate composite materials is significantly affected by the tendency of these materials to delaminate and the fibres to pull from the matrix under the action of machining forces (thrust force and torque).

\section{Delamination analysis}

The delamination develops along the fibre direction and is developed in two phases, the chisel edge action phase and the cutting edge action phase, see fig. 1. The first phase begins when the thrust force of the chisel edge onto the exit surface reaches a critical value and ends when the chisel edge just penetrates the plate. By examining the photographs of the exit surfaces and the finished workpieces, it was found that the chisel edge has a strong effect on the formation of the delamination. A small bulge emerges first in the vicinity of the drilling axis and then develops along the fibre direction of the exit surface. When the bulge grows to a certain degree, the surface layer splits open, the chisel edge penetrates and the second phase, cutting edge action phase, starts. The delamination damage initiated in the first phase further develops due to the continuous pushing and twisting of the cutting edge. The chisel edge cuts the workpiece material with a big negative rake angle and generates over $50 \%$ of the thrust force. Thus the chisel edge plays a key role. [Zhang 2001] a)

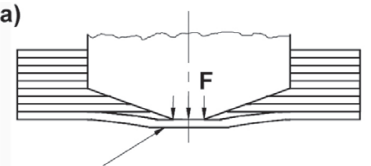

Thrust action of chisel edge b)

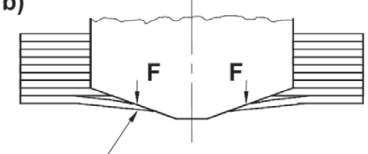

Thrust and twist action of cutting edge
Figure 1. [Zhang 2001]

\subsection{Delamination model for push-out at exit}

A simple model for predicting thrust levels that will induce delamination at exit has been proposed by Hocheng-Dharan [Hocheng 1990, Ozaki 2000]. The delaminated area is assumed to be circular plate clamped on its contour (Fig.2). The equation of the critical thrust force for crack propagation is expressed as follows

$$
\boldsymbol{F}_{\text {del.exit }}(\boldsymbol{h})=\pi \sqrt{32 M G_{I C}}=\pi \sqrt{\frac{8 G_{I C} E_{1} h^{3}}{3\left(1-v_{12}^{2}\right)}},
$$

where $h$ is uncut thickness of material under drill, $G_{I C}$ is critical energy release rate for delamination in Mode $I, E_{1}$ is the modulus of elasticity along the fibre direction [Mathew 1999, Durao 2008] and $v_{12}$ is the Poisson's ratio. To avoid delamination, the thrust force should not exceed this value.

The values given by the equation (1) are continuous with respect to drill position. The thrust force that causes delamination in laminate material must be discrete, since delamination occurs only between laminae, not inside a lamina [Ozaki 2000]. In this case the critical thrust force for crack propagation is as follows

$$
\boldsymbol{F}_{\boldsymbol{D}, \text { del. .exit }}(\boldsymbol{n})=\pi \sqrt{\frac{8 \boldsymbol{G}_{I C} \cdot \boldsymbol{E}_{1}\left(\boldsymbol{n} \cdot \boldsymbol{h}_{t}\right)^{3}}{3\left(1-\boldsymbol{v}_{12}^{2}\right)}},
$$

where $h_{t}$ is the thickness of one layer and $n=h / h_{t}$ is the number of layers that remain undrilled.

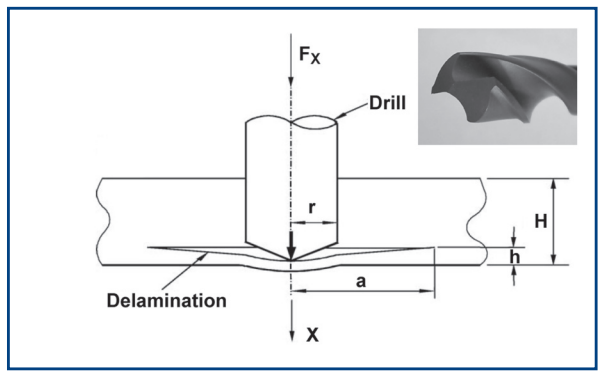

Figure 2. Circular plate model for delamination analysis (twist drill) [Hocheng 2003].

\section{Verification of proposed delamination model}

Experiments with different cutting conditions were done to validate discrete Hocheng-Dharan model of delamination, see Eq. (2). Unidirectional carbon/epoxy laminate fabricated by hand lay-up technique from prepreg was used for experiment, see table 1. Thickness of one lamina $h_{t}=0,15 \mathrm{~mm}$, total thickness $\mathrm{H}=6 \mathrm{~mm} \rightarrow 40$ layers. Holes were machined by HSS drills z10 and go10, geometry is shown in table 2 . Feed per revolution was chosen as follows: $f=0,1$; 0,$2 ; 0,3 \mathrm{~mm}$, revolution was kept constant at the value $\mathrm{n}=1020 \mathrm{~min}^{-1}$, i.e. $v_{c}=32 \mathrm{~m} \cdot \mathrm{min}^{-1}$.

As emerged from the theoretical analysis chisel edge plays a key role in machining process (generates over 50\% of the thrust force and chisel edge push on surface layers). Unfortunately, feed force from chisel edge " $\mathrm{F}_{\mathrm{f} \text {,chisel }}$ "cannot be measured by direct way. For this reason, the holes $10 \mathrm{~mm}$ in diameter were drilled into the full material and then into the material with pre-drilled pilot holes; pilot holes are the same as the chisel edge length. Feed force $F_{f, c h i s e l}$ is equal to difference of measured data between full and pre-drilled hole, see table 3.

After substitution of machined material properties into Eq. (2), the first three values of critical force for crack propagation at the exit are as follows: $F_{D 1, \text { del.exit }}=32,50 \mathrm{~N} ; F_{D 2 \text {, del.exit }}=91,90 \mathrm{~N}$ and $F_{D 3 \text {, del.exit }}=168,80 \mathrm{~N}$. It means in graphical representations, see Fig. 3 that delamination occurs when feed force from chisel edge cross the curves given by Eq. (2). To make the Figure 3 complete the critical delamination force at the entrance is drawn in right area of graph. The drill moves from right to left and at the value $h=0$ chisel edge just penetrates the plate, the same situation occurs in all Figures 4-8. 


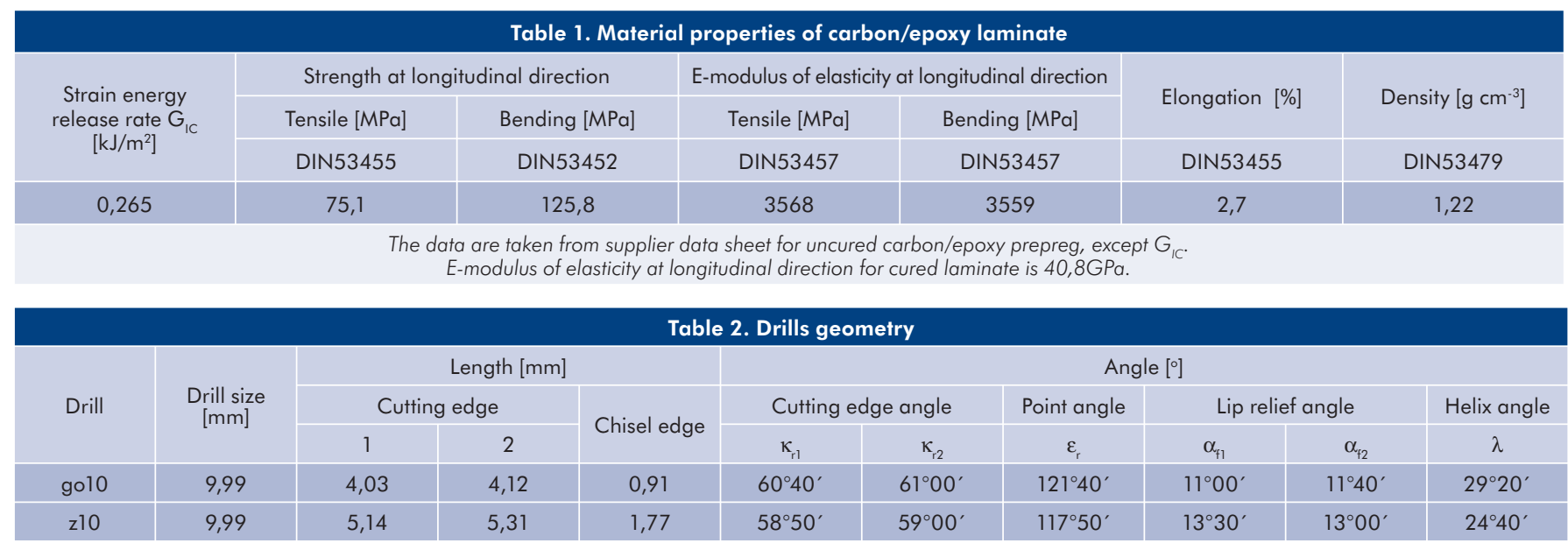

\begin{tabular}{|c|c|c|c|c|c|c|c|}
\hline Drill & $\begin{array}{l}\text { Feed per revolution } \\
\qquad[\mathrm{mm}]\end{array}$ & $\begin{array}{l}\text { Full load of drill } \\
\qquad \mathrm{F}_{f}^{*}[\mathrm{~N}]\end{array}$ & $\begin{array}{l}\text { Pre-drilled chisel } \\
\text { edge } \mathrm{F}_{\mathrm{f}}^{* *}[\mathrm{~N}]\end{array}$ & $\begin{array}{l}\text { Full load of drill } \\
\qquad \mathrm{Mc}^{*}[\mathrm{Nm}]\end{array}$ & $\begin{array}{l}\text { Pre-drilled chisel } \\
\text { edge } \mathrm{Mc}^{* *}[\mathrm{Nm}]\end{array}$ & $\mathrm{F}_{\mathrm{f}, \text { chisel }}=\mathrm{F}_{f}^{*}-\mathrm{F}_{f}^{* *}$ & $\begin{array}{c}M_{c, \text { chisel }}=M c^{*}-M c^{* *} \\
{[\mathrm{Nm}]}\end{array}$ \\
\hline \multirow{9}{*}{ z10 } & \multirow{3}{*}{0,1} & 244 & 175 & 0,723 & 0,705 & 69 & 0,018 \\
\hline & & 251 & 187 & 0,735 & 0,719 & 64 & 0,016 \\
\hline & & 254 & 180 & 0,730 & 0,711 & 74 & 0,019 \\
\hline & \multirow{3}{*}{0,2} & 324 & 198 & 0,990 & 0,940 & 126 & 0,05 \\
\hline & & 319 & 203 & 0,988 & 0,933 & 116 & 0,055 \\
\hline & & 336 & 206 & 0,997 & 0,941 & 130 & 0,056 \\
\hline & \multirow{3}{*}{0,3} & 400 & 221 & 1,420 & 1,370 & 179 & 0,05 \\
\hline & & 409 & 239 & 1,429 & 1,360 & 170 & 0,069 \\
\hline & & 418 & 228 & 1,417 & 1,380 & 190 & 0,037 \\
\hline \multirow{9}{*}{ gol0 } & \multirow{3}{*}{0,1} & 157 & 119 & 0,654 & 0,635 & 38 & 0,019 \\
\hline & & 139 & 109 & 0,642 & 0,630 & 30 & 0,012 \\
\hline & & 150 & 117 & 0,650 & 0,625 & 33 & 0,025 \\
\hline & \multirow{3}{*}{0,2} & 200 & 138 & 0,890 & 0,875 & 62 & 0,015 \\
\hline & & 203 & 133 & 0,899 & 0,867 & 70 & 0,032 \\
\hline & & 210 & 144 & 0,884 & 0,895 & 66 & $-0,011$ \\
\hline & \multirow{3}{*}{0,3} & 265 & 164 & 1,261 & 1,235 & 101 & 0,026 \\
\hline & & 250 & 155 & 1,250 & 1,245 & 95 & 0,005 \\
\hline & & 256 & 166 & 1,257 & 1,235 & 90 & 0,022 \\
\hline
\end{tabular}

From the graph of Fig. 4 result that in case of drill z10 and feeds per revolution $\mathrm{f}=0,1$ and $0,2 \mathrm{~mm}$ only one layer is delaminated but when $\mathrm{f}=0,3 \mathrm{~mm}$ two layers are delaminated. It was also confirmed by measurement of delamination thickness because in case of feed per revolution $\mathrm{f}=0,3 \mathrm{~mm}$ is delamination thickness $\mathrm{h}_{\text {del }}=0,3 \mathrm{~mm}$ and when $\mathrm{f}=0,1$ and $0,2 \mathrm{~mm}$ is delamination thickness equal to thickness of one laminate layer. Measurement also confirmed assumption that delamination occurs only between layers of laminate.

From the graph of Fig. 5 result that in case of drill gol0 and feeds per revolution $\mathrm{f}=0,2$ and $0,3 \mathrm{~mm}$ one layer is delaminated but when $\mathrm{f}=0,1 \mathrm{~mm}$ the delamination should not occurs. In actual fact from

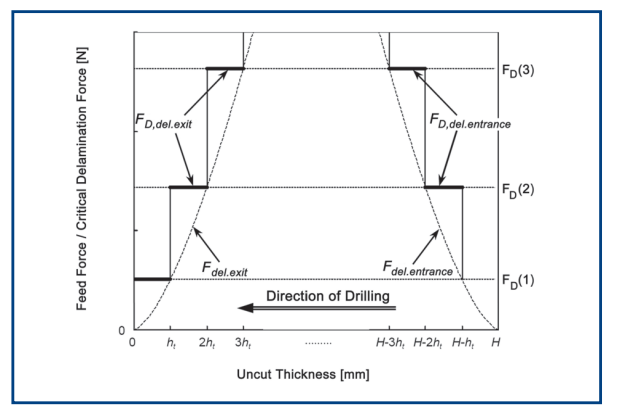

Figure 3. Discrete a continuous critical delamination forces at the entrance and exit [Ozaki 2000] visual check and after measurement is evident that also at the lower feed per revolution $(f=0,1 \mathrm{~mm})$ one layer is delaminated. This fact can be explained as follow:

- besides of chisel edge also the main cutting edge has influence on delamination,

- from the graphs, Fig. 4 and 5 is clear that bulging of uncut material under the chisel edge occurs when the uncut thickness becomes small. Bulging is a nonlinear process and is not considered in the Equation (2) which is based on linear elastic fracture mechanics (LEFM) [Ozaki 2000]. For this reason is necessary to consider the delamination model as simplified.

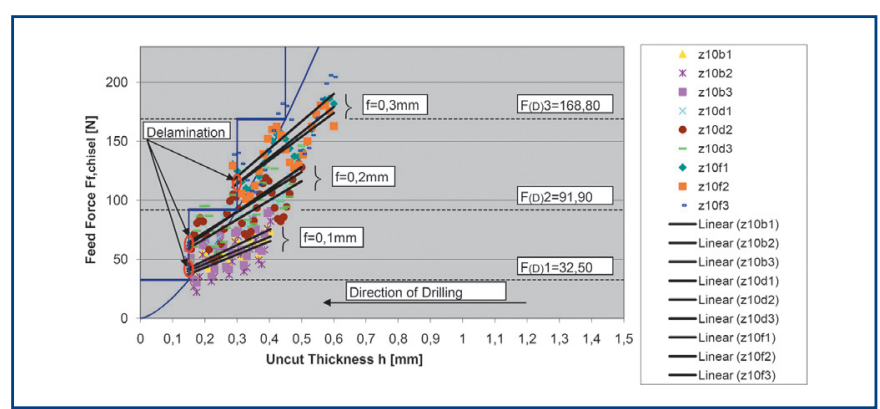

Figure 4. Feed force from chisel edge versus critical delamination force for drill z10 

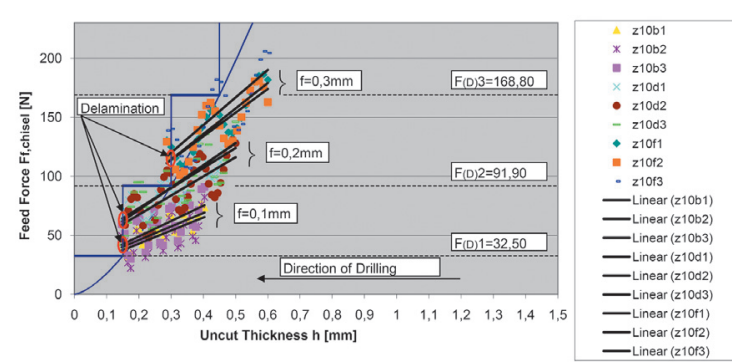

Figure 5. Feed force from chisel edge versus critical delamination force for drill gol0

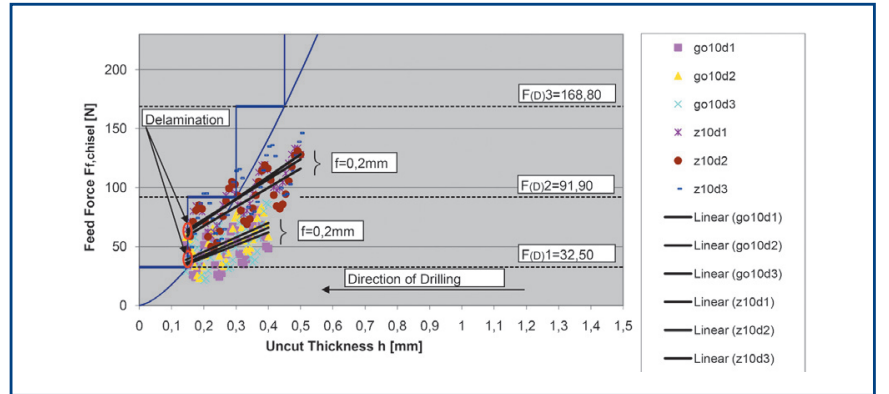

Figure 7. Comparison of drills z 10 and go 10 , feed per revolution $f=0,2 \mathrm{~mm}$

Comparison of feed forces from chisel edges of drills z10 and go10 for each individual feeds per revolution is drawn on Fig. 6-8.

\section{Influence of cutting conditions on delamination}

Selection of proper cutting condition can positively affect the delamination. For this reason, the effect of different parameters was analysed using statistical method Design of Expeiment (DOE). Full factorial design was used in this experiment with four factors at two levels. Analysed factors were as follows: $A$ - feed rate, $B$ - cutting tool geometry, $C$ - cutting speed and $D$ - tool wear. Number of replications was chosen $n=2$. Size of delamination $F_{d}$ was evaluated according equation

$$
\boldsymbol{F}_{d}=\left(\boldsymbol{l}_{1}+\boldsymbol{l}_{2}\right) / 2
$$

where $I_{1}$ a $I_{2}$ are delaminated lengths on both sides of drilled hole [Zhang 2001], see Fig. 9.

Based on Fig. 10 is evident, that factor A (feed rate) has the strongest influence on delamination. Pareto chart display the absolute values of effects and draws a reference line on the chart. All effect that exceed this line are potentially important. The others factors: B (tool geometry), C (cutting speed), D (tool wear) and interaction A.B are also considered to be significant at $95 \%$ confidence level. The interaction A.B can be seen on Fig. 11 in detail.

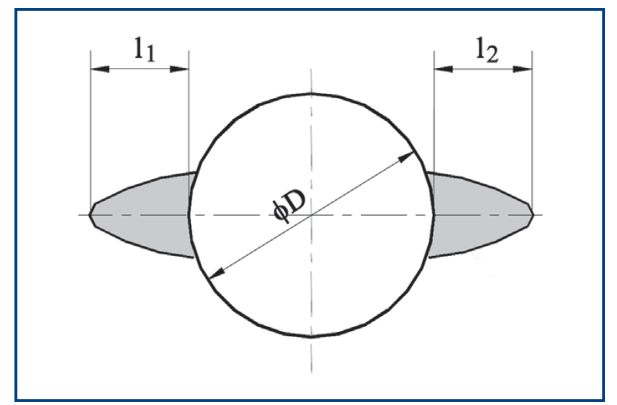

Figure 9. [Zhang 2001]

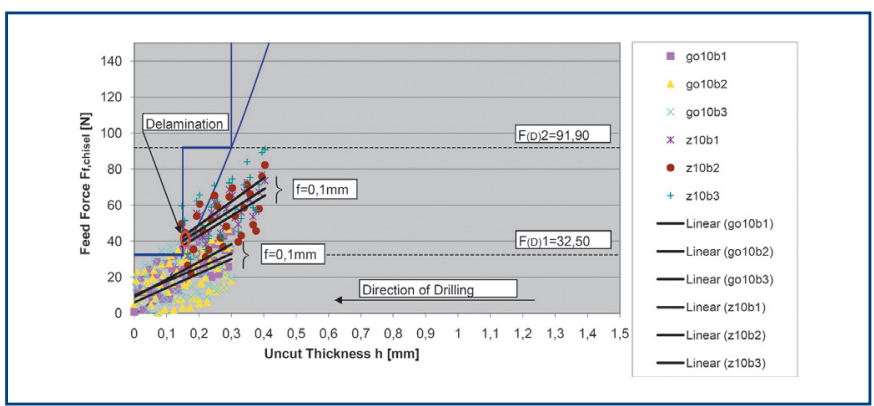

Figure 6. Comparison of drills z10 and go 10 , feed per revolution $f=0,1 \mathrm{~mm}$

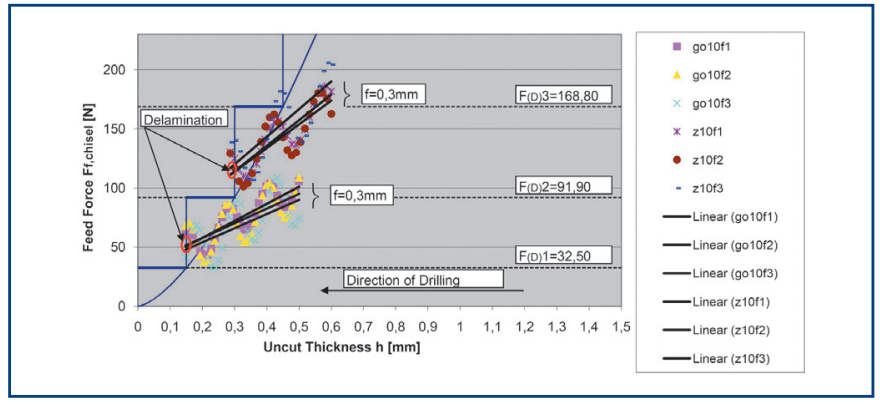

Figure 8. Comparison of drills z10 and go 10 , feed per revolution $f=0,3 \mathrm{~mm}$

\section{Conclusions}

An analysis of delamination damage caused by thrust force (feed force) of twist drill at the exit plane has been described in the present study. Hocheng-Dharan model was found suitable, except of drill gol0 at the feed rate $f=0,1 \mathrm{~mm}$. To avoid delamination, the feed rate should be reduced so that thrust force does not exceed the value given by Hocheng-Dharan equation. Strong effect of feed rate on delamination was also confirmed by analysis of DEO. Sequence of factors significance was evaluated as follows: feed rate, tool wear, tool geometry and cutting speed. Hence, the drill with short chisel edge and sharp cutting edge from cemented carbide or polycrystalline diamond is suitable to choose.

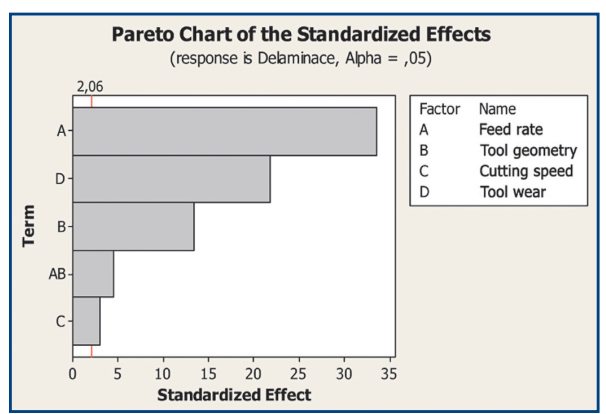

Figure 10.

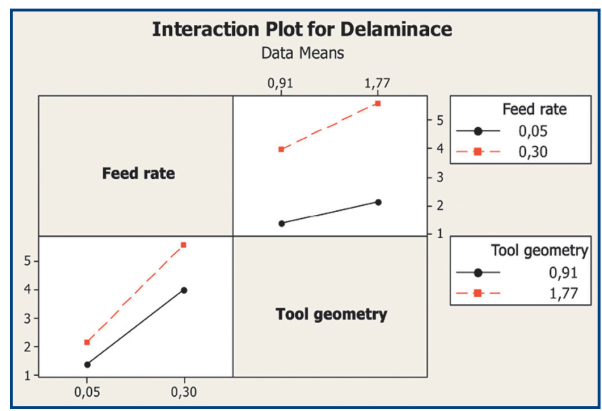

Figure 11 


\section{Acknowledgement}

This work was kindly supported by the Specific Research Grant of BUT, Faculty of Mechanical Engineering, Brno, identity number 361, reg. number FSI-S-10-61.

\section{References}

[Durao 2008] Durao, L.M.P., Magalhaes, A.G., Marques, A.T., Baptista, A.M., Figueiredo, M. Drilling of Fibre Reinforced Plastic Laminates. Materials Science Forum. 2008, Vols. 587-588, pp. 706-710. ISSN 1662-9752. [Hocheng 1990] Hocheng, H., Dharan, C. K. H. Delamination during drilling in composite laminates. Journal of Engineering for Industry. 1990, Vol. 112, pp. 236-239. ISSN 0022-1817.

[Hocheng 2003] Hocheng, H., Tsao, C.C. Comprehensive analysis of delamination in drilling of composite materials with various drill bits. Journal of Materials Processing Technology. 2003, Vol. 140, pp. 335-339. ISSN 0924-0136.
[Mathew 1999] Mathew, J., Ramakrishnan, N., Naik, N.K. Trepanning on unidirectional composites: delamination studies. Composites Part A: Applied Science and Manufacturing. 1999, pp. 951-959. ISSN 1359-835X.

[Ozaki 2000] Ozaki, M. Supervisory Control of Drilling of Composite Materials, Berkeley: University of California, 2000.

[Zhang 2001] Zhang, H., Chen, W., Chen, D., Zhang, L. Assessment of the Exit Defects in Carbon Fibre-Reinforced Plastic Plates Caused by Drilling. Key Engineering Materials. 2001, Vol. 196, pp. 43-52. ISSN 1013-9826.

\section{Contacts:}

Ing. Jan Sedlacek, Brno UT, Faculty of Mechanical Engineering Institute of Manufacturing Technology

Technicka 2, 61669 Brno, Czech Republic tel.: +420541 142 408, e-mail:ysedla10@fme.vutbr.cz 